\title{
Complexes of lutein with bovine and caprine caseins and their impact on lutein chemical stability in emulsion systems: Effect of arabinogalactan
}

\author{
A. Mora-Gutierrez, ${ }^{1}$ R. Attaie, M. T. Núñez de González, Y. Jung, S. Woldesenbet, and S. A. Marquez \\ Cooperative Agricultural Research Center, Prairie View A\&M University, Prairie View, TX 77446
}

\begin{abstract}
Lutein is an important xanthophyll carotenoid with many benefits to human health. Factors affecting the application of lutein as a functional ingredient in low-fat dairy-like beverages ( $\mathrm{pH}$ 6.0-7.0) are not well understood. The interactions of bovine and caprine caseins with hydrophobic lutein were studied using UV/ visible spectroscopy as well as fluorescence. Our studies confirmed that the aqueous solubility of lutein is improved after binding with bovine and caprine caseins. The rates of lutein solubilization by the binding to bovine and caprine caseins were as follows: caprine $\alpha_{\mathrm{S1}}$-IIcasein $34 \%$, caprine $\alpha_{\mathrm{S} 1}$-I-casein $10 \%$, and bovine casein $7 \%$ at $100 \mu M$ lutein. Fluorescence of the protein was quenched on binding supporting complex formation. The fluorescence experiments showed that the binding involves tryptophan residues and some nonspecific interactions. Scatchard plots of lutein binding to the caseins demonstrated competitive binding between the caseins and their sites of interaction with lutein. Competition experiments suggest that caprine $\alpha_{\mathrm{S1}}-\mathrm{II}$ casein will bind a larger number of lutein molecules with higher affinity than other caseins. The chemical stability of lutein was largely dependent on casein type and significant increases occurred in the chemical stability of lutein with the following pattern: caprine $\alpha_{\mathrm{S1}}$-II-casein $>$ caprine $\alpha_{\mathrm{S} 1}-\mathrm{I}$-casein $>$ bovine casein. Addition of arabinogalactan to lutein-enriched emulsions increases the chemical stability of lutein-casein complexes during storage under accelerated photo-oxidation conditions at $25^{\circ} \mathrm{C}$. Therefore, caprine $\alpha_{\mathrm{S} 1}$-II-casein alone and in combination with arabinogalactan can have important applications in the beverage industry as carrier of this xanthophyll carotenoid (lutein).
\end{abstract}

Key words: casein, bovine, caprine, lutein, arabinogalactan

Received May 2, 2017.

Accepted September 6, 2017.

${ }^{1}$ Corresponding author: admora@pvamu.edu

\section{INTRODUCTION}

Carotenoids are primarily symmetrical, C-40, polyisoprenoid structures with an extensive conjugated double-bond system. The C-40 carotenoids can be divided into carotenes, which are hydrocarbons (e.g., $\beta$-carotene), and their oxygenated derivatives, the xanthophylls (e.g., lutein, astaxanthin, zeaxanthin; Sajilata et al., 2008). Lutein, which is mainly extracted from Marigold flowers (Tagetes erecta), has recently come into the limelight because of animal and epidemiological studies that support its eye health benefits (Sasaki et al., 2012). The eye is susceptible to photosensitized damage and adequate intake of lutein can provide protection against photo-injury (Krinsky et al., 2003). The role of lutein is filtration of blue light and functions as an antioxidant (Eisenhauer et al., 2017). As the lutein levels increase in the macula of the eye, a significant decrease will occur in the amount of harmful light rays that reach the retinal cells that produce vision. Therefore, lutein reduces the risk of macular degeneration, an age-related disease of the retina that is a common cause of loss of vision in the elderly. Lutein acts as antioxidant by scavenging free radicals or quenching singlet oxygen, thereby decreasing oxidative stress in the retina (Eisenhauer et al., 2017).

Since humans cannot synthesize carotenoids, it is essential that they eat green leafy vegetables such as kale and spinach as part of their daily diet (Eisenhauer et al., 2017). To achieve a lifetime of excellent vision, a dosage of $10 \mathrm{mg}$ of lutein per day is required (Frede et al., 2014). Although green leafy foods are good sources of the carotenoid lutein, enzymatic degradation of this carotenoid occurs immediately when the leaves are cut. Another source of lutein, and one that is the most bioavailable of all, is the egg (Eisenhauer et al., 2017). However, the segment of the population that has been recommended to control dietary cholesterol intake avoids consumption of eggs. Generally, older consumers are more interested in functional foods than the younger generation to improve health and extend life expectancy. Most functional foods that have been developed are beverages, but several challenges in formulating lutein-rich beverages still exist. 
Stabilizing beverages poses a unique challenge to formulators because of their very dilute nature. Formulators have to find a way of stabilizing sensitive ingredients such as colors, flavors, and micronutrients, many of which may not even be soluble in water, in microgram levels in liters of liquid. A liquid dietary food rich in lutein is difficult to design due to its low oral bioavailability. The poor oral bioavailability of lutein has been a challenge and was ascribed to its low water solubility and chemical stability (Mitri et al., 2011). Emulsion delivery systems have enabled the incorporation of lutein at a high dose with minimal formulation issues (Davidov-Pardo et al., 2016). The use of bovine casein assisted in the emulsion delivery process (Davidov-Pardo et al., 2016). However, caprine casein, due to its different composition (i.e., lower $\alpha_{\mathrm{S} 1}$ - $\mathrm{CN}$ and higher $\beta-\mathrm{CN})$, has been shown to protect algae oil with added carotenoids against oxidation at oil-in-water interfaces (Mora-Gutierrez et al., 2010). The $\beta$-CN fraction of caprine whole casein absorbed to the oil-water interface of emulsions formed a dense interfacial layer surrounding oil droplets, thereby participating in the protective effect against lipid oxidation (Mora-Gutierrez et al., 2010). In the dispersion systems of carotenoids, which are lipophilic molecules with near zero inherent aqueous solubility, there is little understanding about the interactions between caseins from different commercially important ruminant species and the lipid-water interfaces.

A recent study suggests that the amount of exopolysaccharide (EPS), which has beneficial effects on human health produced by cocultures of Streptococcus thermophilus and Lactobacillus bulgaricus, is positively influenced by the presence of caprine $\alpha_{\mathrm{S}_{1}} \mathrm{I}-\mathrm{CN}$ peptides and caprine $\alpha_{S 1}$-II-CN peptides in the culture medium (Mora-Gutierrez, 2016). This report of increased production of EPS by dairy strains of lactic acid bacteria grown in lactobacilli de Man, Rogosa, and Sharpe broth supplemented with caprine $\alpha_{S_{1}}-\mathrm{I}-\mathrm{CN}$ peptides and caprine $\alpha_{\mathrm{S} 1}$-II-CN peptides made these peptides and their parent proteins appealing as possible food ingredients with a potential prebiotic character. Bioactive peptides can be released from the parent protein during gastrointestinal digestion and may interact with Bifidobacterium longum, which is a species of bacteria commonly found in the human intestine. Levels of Bifidobacterium decline with age, therefore, a food ingredient that on ingestion has the ability to increase levels of bifidobacteria (Fiedorowicz et al., 2016) and production of EPS (Salazar et al., 2009) is a potential food ingredient in the prevention of digestive problems such as constipation and abdominal discomfort.

In this work, the interactions between lutein and the caseins isolated from bovine and caprine milks were studied by turbidity measurements and fluorescence spectroscopy. Furthermore, the effects of lutein-casein complexes on lutein's chemical stability in lutein-enriched emulsions during storage under conditions for accelerated photo-oxidation were also compared. Moreover, due to the importance of enhancing lutein water solubility and chemical stability in low-fat dairy-like beverages, we used a water-soluble polysaccharide (i.e., arabinogalactan). Arabinogalactan, a highly branched polysaccharide polymer composed of galactose and arabinose in a 6:1 ratio, has been shown to enhance the solubility and photo-stability of lutein in aqueous solutions (Polyakov and Kispert, 2015). Additionally, the effects of caprine $\alpha_{\mathrm{S} 1}-\mathrm{I}-\mathrm{CN}$ and caprine $\alpha_{\mathrm{S} 1}-\mathrm{II}-\mathrm{CN}$ on the chemical stability of lutein in lutein-enriched emulsions were also examined.

\section{MATERIALS AND METHODS}

\section{Materials}

A commercial preparation of lutein consisting of $20 \%$ (wt/wt) lutein dissolved in corn oil was a gift from Hoffman La Roche (Pleasanton, CA). Mazola corn oil was purchased from a local supermarket. A lutein standard for chromatography analysis was purchased from Extrasynthèse SA (Genay, France). Arabinogalactan, L-tryptophan, ethanol, thimerosal, phenylmethanesulfonyl fluoride, and monobasic potassium phosphate were purchased from Sigma-Aldrich (St. Louis, MO). Dimethyl sulfoxide (DMSO) was purchased from Fisher Scientific (Pittsburgh, PA). Deionized water, prepared by passing distilled water over a mixed bed of cation-anion exchanger, was used throughout this study.

\section{Preparation of Bovine and Caprine Caseins}

Caseins were prepared from the milk of a Jersey cow and French-Alpine goats. The samples of caprine milk were collected from individual French-Alpine animals that were raised at the International Goat Research Center in Prairie View A\&M University, Texas. The caprine milk caseins were selected based on yielding high levels of $\alpha_{\mathrm{S1}^{-}} \mathrm{CN}$ as determined by reversed-phase HPLC (Mora-Gutierrez et al., 1991). The equipment for HPLC consisted of a Waters 600 multi-solvent delivery system, a 481 variable wavelength LC spectrophotometer and a 740 data module (Waters Corporation, Milford, MA).

Caseins were isolated from $2 \mathrm{~L}$ of fresh, uncooled milk to which phenylmethanesulfonyl fluoride $(0.1 \mathrm{~g} / \mathrm{L})$ was added immediately to retard proteolysis. The milk was centrifuged at 4,000 $\times g$ for $10 \mathrm{~min}$ at room tem- 
perature to remove the cream fraction using a Beckman Model J2-21 (Beckman Instruments Inc., Palo Alto, CA) centrifuge. Skim milk $(500 \mathrm{~mL})$ was diluted with an equal volume of distilled water and warmed to $37^{\circ} \mathrm{C}$. Casein was precipitated by gradual addition of $1 \mathrm{~N} \mathrm{HCl}$ to $\mathrm{pH}$ 4.5. The precipitate was homogenized with a handheld homogenizer (Biospec Products Inc., Bartlesville, OK) at low speed and dissolved by addition of $1 M \mathrm{KOH}$ to yield a solution of $\mathrm{pH}$ 7.0. The casein was precipitated again, washed, and then re-suspended. The casein was subsequently cooled to $4^{\circ} \mathrm{C}$ and centrifuged at 100,000 $\times g$ for $30 \mathrm{~min}$ to remove residual fat using a Beckman Optima XL-A (Beckman Instruments Inc., Palo Alto, CA) analytical ultracentrifuge. The integrity of the samples was confirmed by SDS-PAGE and densitometry was used to assess the relative concentration of casein components (Basch et al., 1989). The SDS-PAGE of skim milk proteins was carried out on a PhastSystem (Pharmacia, Piscataway, NJ). Densitometry of the gels was carried out on a Bio-Rad Model 222 gel scanner (Bio-Rad Laboratories, Hercules, CA). Data were analyzed using software programs supplied by the manufacturer.

\section{Sample Preparation for Turbidity Measurements}

A $2 \mathrm{~m} M$ stock solution of lutein in ethanol was prepared and stored at $4^{\circ} \mathrm{C}$. To prepare the lutein samples (control) in the concentration range of 5 to $100 \mu M$ lutein, stock $2 \mathrm{~m} M$ lutein solution was added dropwise to $5 \mathrm{~m} M$ phosphate buffer ( $\mathrm{pH} 7.0$ ) under constant stirring. To prepare the lutein-casein samples, stock 2 $\mathrm{m} M$ lutein solution was added dropwise to the casein solutions in $5 \mathrm{~m} M$ phosphate buffer ( $\mathrm{pH} 7.0$ ) under magnetic stirring to get different concentration of lutein $(5,10,20,40,60,80$, and $100 \mu M)$, whereas casein remained constant at $0.5 \mathrm{mg} / \mathrm{mL}$. All samples were mixed by magnetic stirring and then incubated at $25 \pm$ $1^{\circ} \mathrm{C}$ for $1 \mathrm{~h}$ before analysis.

\section{Turbidity Measurements}

Turbidity was determined from the transmission at $500 \mathrm{~nm}$ using a Beckman model DU-530 UV/visible spectrophotometer (Beckman Instruments Inc., Fullerton, CA) and expressed as 100\% transmission. All experiments were performed in triplicate at $25 \pm 1^{\circ} \mathrm{C}$.

\section{Fluorescence Studies}

The fluorescence studies were performed on a Shimadzu spectrofluorophotometer RF-5000 (Shimadzu Corporation, Columbia, MD) equipped with a calcula- tor and plotter. The AA L-tryptophan and the bovine casein or caprine casein were excited at $280 \mathrm{~nm}$ and their emission spectra were recorded between 300 and $400 \mathrm{~nm}$. Emission spectra were recorded in the concentration range mentioned in the legend of Figure 2.

\section{Fluorescence Quench Titration and Determination of Binding of Lutein to Caseins}

The fluorescence titration and calculations of the association constant of lutein with bovine and caprine caseins were performed exactly as described by Levine (1977). The titration consisted of adding aliquots of lutein to the L-tryptophan/casein solutions and measuring the decrease in tryptophan fluorescence after each addition. In almost all cases, the region of interest was the lutein/(tryptophan/casein) ratio of 0 to 5.0. At least 40 points were obtained in the region of interest. The fluorescence quench curves were plotted with the molar ratio of lutein to L-tryptophan/casein on the abscissa and the fluorescence on the ordinate. Fractional quench (Q) was calculated from these curves by this equation $\Delta \mathrm{Q}=\left(\mathrm{F}_{\mathrm{o}}-\mathrm{F}\right) / \mathrm{m}$, where $\mathrm{F}$ is the fluorescence at the molar ratio (lutein:tryptophan/protein) of $1, \mathrm{~F}_{\mathrm{o}}$ is the fluorescence at zero ratio, and $\mathrm{m}$ is the maximal quench of the fluorescence. The fluorescence quench curves were used to generate Scatchard plots and analysis of the Scatchard plots was performed, as described by Steiner et al. (1966), to determine the association constant and the number of moles of lutein bound per mole of L-tryptophan or casein.

\section{Emulsion Preparation}

A low-fat dairy-like beverage (Davidov-Pardo et al., 2016) was prepared as follows: an organic phase was prepared by diluting $2.5 \%$ (wt/wt) of the commercial lutein in corn oil. An aqueous phase was prepared by dispersing 1\% (wt/wt) of lyophilized bovine casein or caprine casein into the aqueous buffer solution $(5 \mathrm{mM}$ phosphate, $\mathrm{pH}$ 7.0). A coarse emulsion of oil-in-water was prepared by mixing the organic phase $(10 \%$, wt/ wt) and the aqueous phase (90\%, wt/wt) using a handheld homogenizer (Biospec Products Inc., Bartlesville, OK) at low speed. In emulsions with added arabinogalactan, $2.5 \%$ (wt/wt) arabinogalactan was added to the aqueous phase before emulsification. The coarse emulsion was then homogenized 5 times at $82.74 \mathrm{MPa}$ $(12,000 \mathrm{psi})$ through a high-pressure TC5 homogenizer (Stansted Fluid Power, Harlow, UK). The fine emulsion produced was then diluted $(1: 1, \mathrm{vol} / \mathrm{vol})$ with buffer solution containing an antimicrobial agent [ $5 \mathrm{~m} M$ phosphate buffer, $\mathrm{pH}$ 7.0, $1 \mathrm{~m} M$ (wt/vol) thimerosal]. The final diluted emulsions that were used for the stability 
studies contained $5 \%$ (wt/wt) oil phase and $250 \mathrm{mg} / \mathrm{L}$ of lutein.

\section{Conditions for Accelerated Photo-Oxidation}

The lutein-enriched emulsions prepared with bovine and caprine caseins were exposed to lighted conditions (fluorescent, daylight type; approximated 2,550 Lx) at $25^{\circ} \mathrm{C}$ for $96 \mathrm{~h}$ (Faraji and Lindsay, 2005). Samples (100 g) were layered in aluminum pans, covered with transparent polymer wrap, and placed under the lighting.

\section{Physical Characterization of the Emulsion}

The particle size of the oil droplets in the luteinenriched emulsions was measured at 1,48 , and $96 \mathrm{~h}$ after homogenization with a SALD-2101 laser diffraction particle analyzer (Shimadzu Corporation, Columbia, MD). The charge of the oil droplets in the lutein-enriched emulsion (zeta potential, $\zeta ; \mathrm{mV}$ ) was measured with a Zetasizer nano ZS (Malvern Instruments, Worcestershire, UK). Samples were diluted 100 times in $5 \mathrm{~m} M$ phosphate buffer at $\mathrm{pH}$ 7.0. All measurements were carried out in triplicate at $25 \pm 1^{\circ} \mathrm{C}$.

\section{Chemical Stability of Lutein}

The chemical stability of lutein was assessed by measuring the concentration of lutein in the luteinenriched emulsions during storage under accelerated photo-oxidation at $25^{\circ} \mathrm{C}$ for $96 \mathrm{~h}$. The concentration of lutein was determined from absorbance measurements at $460 \mathrm{~nm}$ using a Beckman UV/visible model DU-530 spectrophotometer (Beckman Instruments Inc., Fullerton, CA). To prepare the samples for the spectrophotometric measurements, the lutein-enriched emulsions were diluted 100 times in DMSO $(50 \mu \mathrm{L}$ of emulsion was diluted into $4.95 \mathrm{~mL}$ of DMSO). The DMSO was used because it dissolves lutein, oil, and protein to form transparent solutions suitable for UV/visible analysis. The emulsion without lutein was used as a blank. A calibration curve was constructed by dissolving lutein standards in DMSO within a range from 0.5 to $5 \mathrm{mg} / \mathrm{L}$.

\section{Statistical Analysis}

All experiments were performed in triplicate and the data are expressed as the means and standard error. Turbidity data were analyzed by 2-way ANOVA with Dunnett's post hoc test using the PROC General Linear Model procedure of SAS (version 9.3, SAS Institute Inc., Cary, NC) at a significance level of $\alpha=0.05 \%$. To evaluate the chemical stability of lutein-enriched emulsions prepared with bovine and caprine caseins and the polysaccharide arabinogalactan under different storage times, data were analyzed as a factorial arrangement, 3 (casein type) $\times 2$ (with or without arabinogalactan) $\times 5$ (stored time), using PROC General Linear Model. Casein type (bovine, caprine $\alpha_{\mathrm{S} 1}-\mathrm{I}$, and caprine $\alpha_{\mathrm{S} 1}-\mathrm{II}$ ), additive (with or without arabinogalactan), and storage time $(1,24,48,72$, and $96 \mathrm{~h})$ were the main effects of the data. Analysis of variance and Tukey multiple comparison test were used to determine statistical differences $(P<0.05)$ among the main effects and their interactions.

\section{RESULTS AND DISCUSSION}

\section{Characterization of Bovine and Caprine Caseins}

The bovine and caprine caseins used in this study had different composition in terms of $\alpha_{\mathrm{S}_{1}} \mathrm{CN}, \alpha_{\mathrm{S}_{2}} \mathrm{CN}$, $\beta-\mathrm{CN}$, and $\kappa-\mathrm{CN}$ (Table 1 ). The major source of variation in the caprine caseins is the $\alpha_{S 1}$-fraction, followed by that of the $\alpha_{\mathrm{S} 2}$ fraction (Ambrosoli et al., 1988). The $\beta$-CN content of the $\alpha_{\mathrm{S} 1}-\mathrm{I}-\mathrm{CN}$ and $\alpha_{\mathrm{S} 1}-\mathrm{II}-\mathrm{CN}$ isolated from caprine milks was markedly higher than that of bovine casein (Table 1). $\beta$-Casein is the most hydrophobic fraction of whole casein (Kumosinski et al., 1993), and this property makes $\beta$-CN-rich whole caseins such as those of caprine $\alpha_{\mathrm{S}_{1}} \mathrm{I}-\mathrm{CN}$ and $\alpha_{\mathrm{S} 1}-\mathrm{II}-\mathrm{CN}$ (Table 1) suitable candidates as encapsulating agents for lipophilic molecules such as n-3 fatty acids (MoraGutierrez et al., 2014).

\section{Turbidity of Lutein and Lutein-Casein Complex}

The complex formed between lutein and bovine casein may have protected the carotenoid molecule from light and temperature degradation (Yi et al., 2016). Besides, this type of encapsulation seems to have increased lutein apparent solubility in water significantly (Yi et al., 2016). To test this hypothesis, turbidity measurements were performed to evaluate the potentials of caprine $\alpha_{\mathrm{S} 1}-\mathrm{I}-\mathrm{CN}$ and $\alpha_{\mathrm{S} 1}-\mathrm{II}-\mathrm{CN}$ to form lutein-casein complexes capable of increasing the apparent solubility

Table 1. Casein distribution of caprine caseins compared with a typical bovine casein ${ }^{1}$

\begin{tabular}{lrcccr}
\hline & \multicolumn{5}{c}{ Casein fraction (\%) } \\
\cline { 2 - 6 } Sample & $\alpha_{\mathrm{S} 2}$ & $\alpha_{\mathrm{S} 1}{ }^{*}$ & $\alpha_{\mathrm{S} 1} *$ & $\beta$ & \multicolumn{1}{c}{$\kappa$} \\
\hline Caprine casein high in $\alpha_{\mathrm{S} 1}-\mathrm{I}$ & 9.2 & 4.0 & 21.1 & 51.6 & 13.8 \\
Caprine casein high in $\alpha_{\mathrm{S} 1}$-II & 5.3 & - & 25.6 & 60.6 & 9.6 \\
Bovine casein & 12.1 & - & 39.5 & 37.2 & 11.2 \\
\hline${ }^{1}$ Densitometry. & & & \\
$*$ Altered SDS-PAGE mobility may represent a truncated version of \\
$\alpha_{\mathrm{S} 1}$-CN.
\end{tabular}

Journal of Dairy Science Vol. 101 No. 1, 2018 
of lutein in the aqueous phase. The turbidity data of lutein alone and lutein-casein complexes are presented in Figure 1. Due to the poor solubility of lutein in water, lutein aggregation is expected to occur in the aqueous phase. This lutein aggregation phenomenon leads to relatively higher turbidity measurements in the control. Compared with the control (lutein alone), the turbidity of lutein-casein complexes for all the treatments were significantly lower $(P<0.05)$ at the same concentrations of lutein from 5 to $100 \mu M$. The turbidity of lutein-casein complexes made with the bovine and caprine $\alpha_{\mathrm{S} 1}-\mathrm{I}-\mathrm{CN}$ were significantly higher $(P>0.05)$ than those made with caprine $\alpha_{\mathrm{S} 1}-\mathrm{II}-\mathrm{CN}$ at the same concentrations (Figure 1). These results indicated that more lutein was bound with caprine $\alpha_{\mathrm{S} 1}-\mathrm{II}-\mathrm{CN}$ than any other caseins.

\section{Fluorescence Quench Titration and Determination of Binding of Lutein to Bovine and Caprine Caseins}

The encapsulation of liposoluble carotenoids (lutein) in milk proteins (i.e., the caseins) may be through the hydrophobic interactions, van der Waals attraction, or hydrogen bonds. Fluorescence spectroscopy is a technique widely used to study interactions between proteins and small molecules such as resveratrol (Liang et al., 2008; Acharya et al., 2013), folic acid (Liang and Subirade, 2010), and vitamin E (Liang et al., 2011). Tryptophan is one of the major chromophores among the naturally occurring AA and is responsible for the absorbance shown by proteins at $280 \mathrm{~nm}$. When excited at its absorption maximum of $280 \mathrm{~nm}$, tryptophan was found to exhibit a fluorescence emission spectrum with a peak at $375 \mathrm{~nm}$. Milk proteins (caseins and whey proteins) exhibit fluorescence when exposed to this technique. The intrinsic fluorescence of casein is almost solely contributed by tryptophan because the fluorescence of phenylalanine has a very low quantum yield and the fluorescence of tyrosine is almost quenched if it is ionized or located near an amino group, a carboxyl group, or a tryptophan (Lakowicz and Weber, 1973; Lakowicz, 2000). In bovine milk, the major whey protein $\beta-L G$ contains 2 tryptophan residues, and the minor whey protein $\alpha$-LA has 4 tryptophan residues (Kelkar et al., 2010), whereas $\alpha-C N$ has 2 tryptophan residues, and $\beta-\mathrm{CN}$ and $\kappa-\mathrm{CN}$ have 1 tryptophan residue each (Kumosinski et al., 1993). However, caprine milk proteins, in particular the caseins, have many sig-

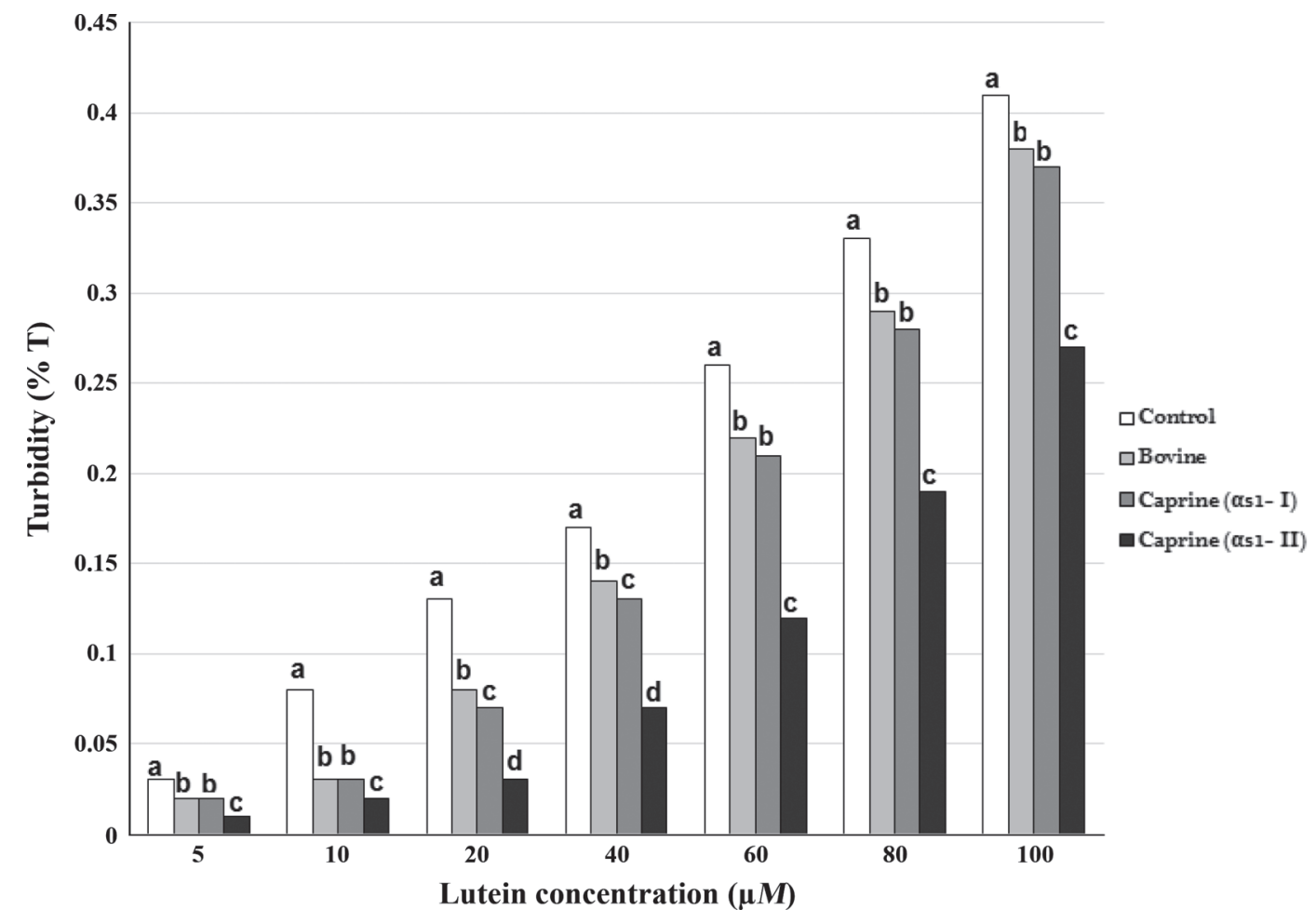

Figure 1. Turbidity of lutein at different concentrations $(5,10,20,40,60,80$, and $100 \mu M)$ alone (control) and in the presence of bovine and caprine caseins $(0.5 \mathrm{mg} / \mathrm{mL})$ in $5 \mathrm{mM}$ phosphate buffer solutions at $\mathrm{pH} 7.0$. Means within each lutein concentration with different lowercase letters $(\mathrm{a}-\mathrm{c})$ are significantly different $(P<0.05)$. 
nificant differences in their AA compositions compared with the milk of other mammalian species, especially in relative proportions of the various casein fractions $\left(\alpha_{\mathrm{S} 1}-\mathrm{CN}, \alpha_{\mathrm{S}^{-}} \mathrm{CN}, \beta-\mathrm{CN}\right.$, and $\left.\kappa-\mathrm{CN}\right)$ and in their genetic polymorphisms (Jaubert and Martin, 1992; Galliano et al., 2004; Selvaggi et al., 2014). Therefore, AA sequences located in homologous positions in homologous caseins may be different in caprine milk. In this study, the existence of such differences in caprine milk caseins from bovine milk caseins is suggested but not proven.

The changes in the fluorescence emission spectrum of caprine $\alpha_{\mathrm{S} 1}$-II-CN in the presence of different concentrations of lutein made with phosphate buffer solutions at pH 7.0 are shown in Figure 2. When a solution of caprine $\alpha_{\mathrm{S} 1}$-II-CN was excited at its absorption maximum of $280 \mathrm{~nm}$, a fluorescence emission spectrum with a maxima at $345 \mathrm{~nm}$ was observed. Addition of increasing concentrations of lutein to caprine $\alpha_{\mathrm{S} 1}-\mathrm{II}-\mathrm{CN}$ resulted in a progressive quenching of the fluorescence emission. The results are suggestive of binding of lutein to caprine $\alpha_{\mathrm{S} 1}-\mathrm{II}-\mathrm{CN}$. The fractional quench was calculated as described in the Materials and Methods. These data were used to construct Scatchard plots for determining the binding of lutein to tryptophan. The Scatchard plot for the binding of lutein to L-tryptophan is shown in Figure 3a. An analysis of this plot revealed that 2.19 mol of lutein are able to bind to 1 mol of L-tryptophan and the association constant of such binding is $4.7 \times$ $10^{7} M^{-1}$ (Table 2). Fluorescence quenching titration of the bovine and caprine caseins was performed by adding increasing concentrations of lutein in exactly the same way as was done with L-tryptophan and the subsequent Scatchard plots are shown in Figures 3b-d. The analysis of Scatchard plots as tabulated in Table 2 revealed that $5.58 \mathrm{~mol}$ of lutein binds to $1 \mathrm{~mol}$ of caprine $\alpha_{\mathrm{S} 1}$-II, whereas $2.89 \mathrm{~mol}$ of lutein binds to $1 \mathrm{~mol}$ of bovine casein, and $2.82 \mathrm{~mol}$ of lutein binds to $1 \mathrm{~mol}$ of caprine $\alpha_{\mathrm{S} 1}-\mathrm{I}-\mathrm{CN}$.

The analysis of the association constants of lutein for the bovine and caprine caseins (Table 2) also showed a variation, which appears not to be related to their tryptophan content. The interesting result is that the association constants for tryptophan-containing caprine $\alpha_{\mathrm{S} 1}-\mathrm{I}-\mathrm{CN}$ and caprine $\alpha_{\mathrm{S1}}$-II-CN were quite similar (5.7 $\times 10^{7} M^{-1}$ and $5.010^{7} M^{-1}$, respectively). However, the association constant for tryptophan-containing bovine casein was quite low $\left(1.4 \times 10^{7} M^{-1}\right)$ compared with caprine caseins. Reasons for this could be based in structural differences as evidenced by circular dichroism spectroscopy (data not shown). The solubility-related, lutein-binding properties of the potassium forms of the caprine casein submicelles, in the absence of $\mathrm{Ca}^{2+}$, are in part determined by the hydrophobic interactions of the dominant protein, $\beta$-CN. The unique assembly of casein submicelles provides a sufficient nonpolar environment for the bound lutein molecules. Casein submicelles consist of a mixture of proteins, and they are natively unfolded proteins, so it is difficult to predict the exact position of binding of lutein molecules. Taking all this information into account, these results may suggest a complex mode of binding of lutein to bovine casein and the 2 caprine caseins, which may involve, in addition to tryptophan residues, some nonspecific interactions. Moreover, the association constants of lutein-casein complexes of caprine $\alpha_{\mathrm{S} 1}-\mathrm{I}-\mathrm{CN}$ and $\alpha_{\mathrm{S} 1}-\mathrm{II}-$ $\mathrm{CN}$ were greater than that of lutein-casein complexes of bovine casein, which indicate that caprine $\alpha_{\mathrm{S} 1}-\mathrm{I}-\mathrm{CN}$ and $\alpha_{\mathrm{S} 1}$-II-CN have higher affinities than bovine ca-

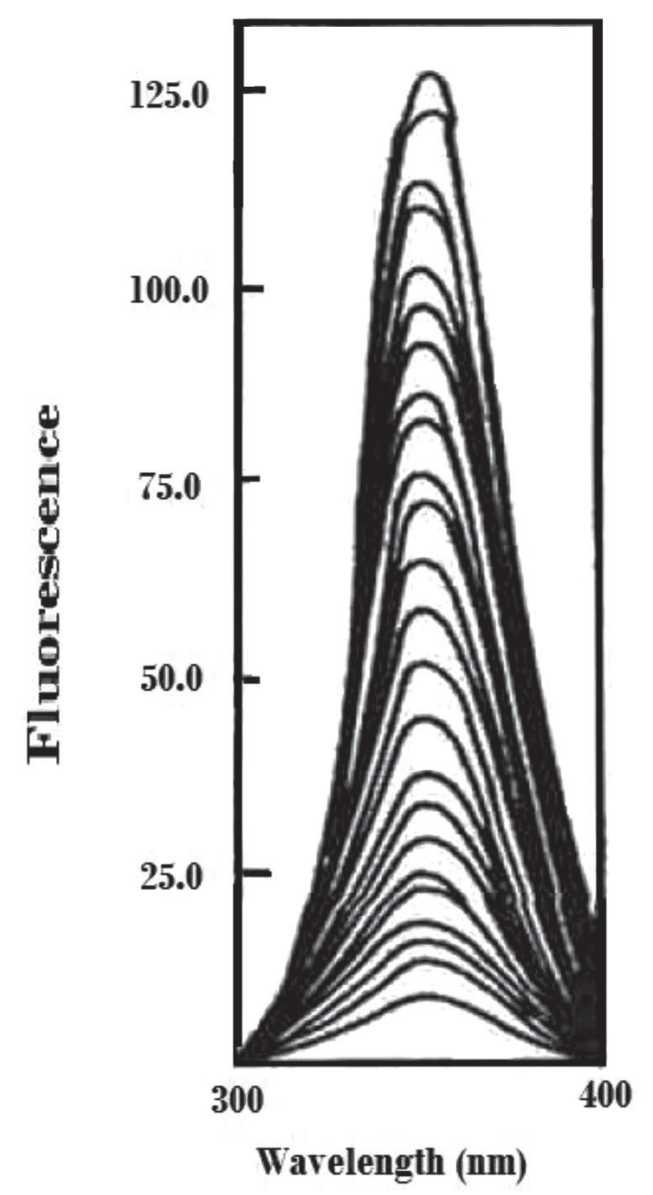

Figure 2. Fluorescence emission spectra of caprine $\alpha_{\mathrm{S} 1}-\mathrm{II}-\mathrm{CN}$ in the presence of lutein. Caprine $\alpha_{\mathrm{S} 1}-\mathrm{II}-\mathrm{CN}$ (in $5 \mathrm{~m} M$ phosphate buffer, $\mathrm{pH}$ 7.0) was excited at $280 \mathrm{~nm}$ and the emission spectra were recorded between 300 and $400 \mathrm{~nm}$. Traces, from top to bottom, are caprine $\alpha_{\mathrm{S1}^{-}}$ II-CN alone $(1 \mu M), \alpha_{\mathrm{S} 1}$-II-CN:lutein molar ratio 1:0.1, 1:0.2, 1:0.4, 1:0.6, 1:0.8, 1:1, 1:1.2, 1:1.5, 1:1.7, 1:2, 1:2.5, 1:3, 1:4, 1:5, 1:6, 1:7, 1:8, $1: 10,1: 11,1: 12,1: 13,1: 14$, and $1: 15$, respectively. 

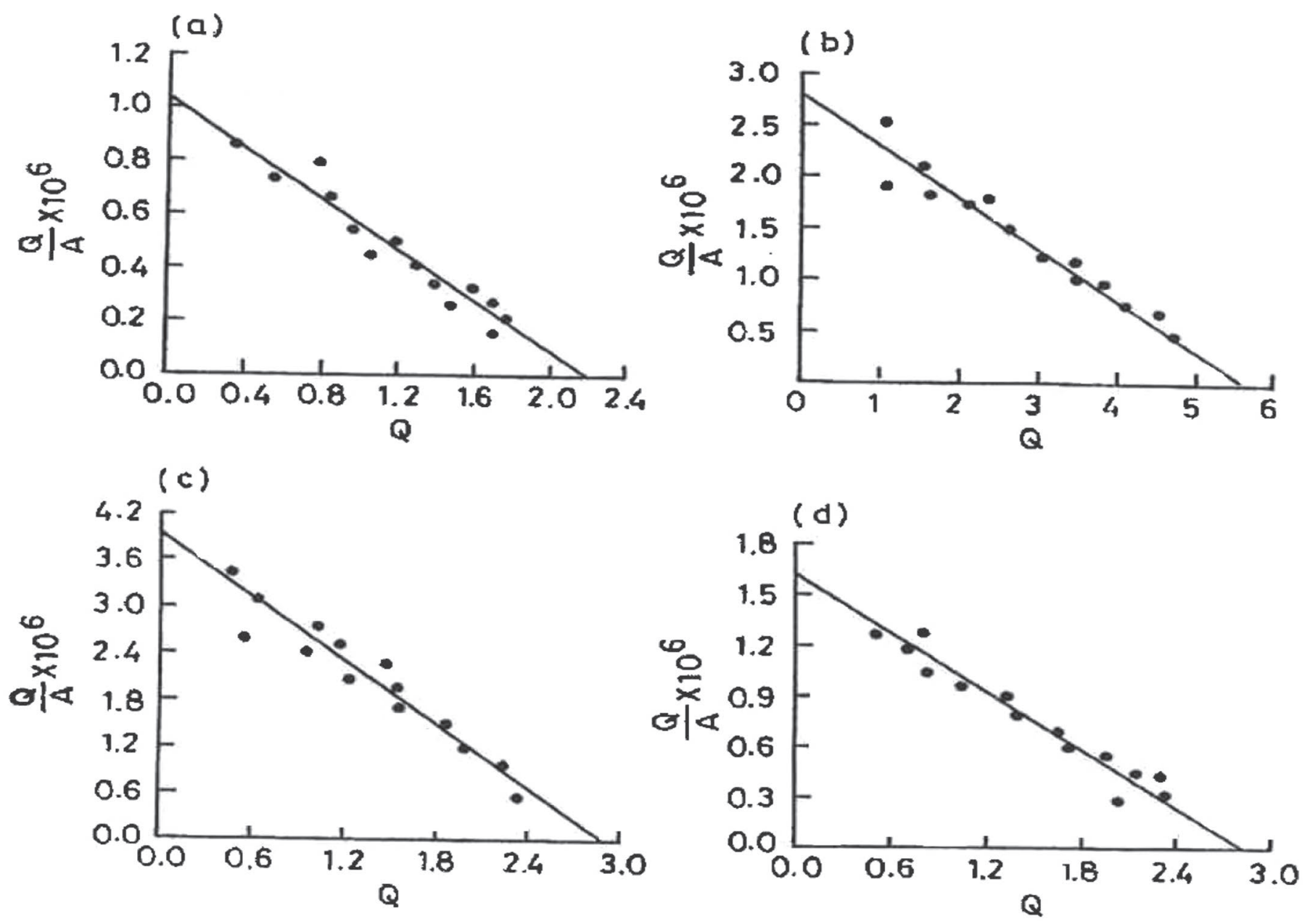

Figure 3. Scatchard plots for binding of lutein to the AA L-tryptophan and the bovine and caprine caseins. Fluorescence titration of bovine and caprine caseins was performed by adding increasing amounts of lutein to L-tryptophan/casein solutions. These data were used to generate

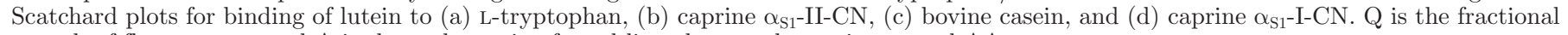
quench of fluorescence, and $\mathrm{A}$ is the molar ratio of total ligand to total protein or total AA.

sein with hydrophobic bioactive molecules (Zhang and Zhong, 2012).

The association constants of lutein for bovine casein and the 2 caprine caseins are of the order of $10^{7} \mathrm{~L} /$ mol (Table 2). Many drugs (synthetic organic anions) have association constants of approximately $10^{4} M^{-1}$ for physiological proteins, whereas the same antibodies for their antigens are of the order of $10^{9} \mathrm{M}^{-1}$ (Meyer and Guttman, 1968). This would suggest that binding of lutein to proteins may not be stereospecific, as in the case of antibodies, but it is still stronger than that observed for nonspecific, electrostatic interactions. This, in part, is accounted by binding of lutein to tryptophan. The results of Table 2 are not very suggestive of tryptophan-specific binding of lutein to milk proteins (the caseins). Instead it appears that lutein, in addition to tryptophan, may bind to other AA and, also, nonspecifically to proteins. As mentioned above, structural changes may make the caprine $\alpha_{\mathrm{S1}}$-II-CN binding site different than those of caprine $\alpha_{\mathrm{S} 1}-\mathrm{I}-\mathrm{CN}$ and bovine casein.

Table 2. Calculated association constants $\left(\mathrm{K}_{\mathrm{a}}\right)$ for the lutein-casein complexes of bovine and caprine caseins and the number of moles of bound lutein per mole of casein molecules ${ }^{1}$

\begin{tabular}{lccc}
\hline AA/casein & $\begin{array}{c}\text { Number of } \\
\text { Trp residues }\end{array}$ & $\begin{array}{c}\text { Association constant } \\
\left(\mathrm{K}_{\mathrm{a}} ; \mathrm{L} \cdot \mathrm{mol}^{-1}\right)\end{array}$ & $\begin{array}{c}\text { Moles of lutein/ } \\
\text { moles of casein }\end{array}$ \\
\hline L-Trp & 1 & $4.7 \times 10^{7}$ & 2.19 \\
Bovine & 4 & $1.4 \times 10^{7}$ & 2.89 \\
Caprine $\alpha_{\mathrm{S} 1}-\mathrm{I}$ & $\mathrm{NA}$ & $5.7 \times 10^{7}$ & 2.82 \\
Caprine $\alpha_{\mathrm{S} 1}-\mathrm{II}$ & $\mathrm{NA}$ & $5.0 \times 10^{7}$ & 5.58 \\
\hline
\end{tabular}

${ }^{1}$ All the values were calculated from the Scatchard plots given in Figure 3.

${ }^{2}$ The AA sequences of caprine $\alpha_{\mathrm{S} 1} \mathrm{I}$ and $\alpha_{\mathrm{S} 1}$-II-CN are not available (NA). 


\section{Physical Stability of Lutein Emulsions Prepared with Bovine and Caprine Caseins}

The physical stability of lutein-enriched emulsions prepared with bovine and caprine caseins are needed before comparisons of chemical stability of lutein could be made. The mean particle diameters of oil droplets in the lutein-enriched emulsions stabilized by bovine and caprine caseins ranged from 205.94 to $206.56 \mathrm{~nm}$ at $\mathrm{pH} 7.0$ (Table 3 ). The casein type did not affect $(P$ $>0.05)$ particle size diameters of oil droplets in luteinenriched emulsions. The mean particle size of oil droplets in lutein-enriched emulsions was significantly lower $(P<0.05)$ with added arabinogalactan. Moreover, we observed no significant differences $(P>0.05)$ in the particle sizes of oil droplets in lutein-enriched emulsions during 1, 48, and $96 \mathrm{~h}$ of storage under accelerated photo-oxidation conditions at $25^{\circ} \mathrm{C}$. The zeta potentials of the caseinate-coated oil droplets in the lutein-enriched emulsions were negative at $\mathrm{pH} 7.0$ (Table 3). It should be noted here that emulsions containing protein-coated lipid droplets are mainly stabilized by electrostatic repulsion (Dickinson, 2010). The zeta potentials of the oil droplets in the lutein-enriched emulsions prepared with caprine caseins were not different $(P>0.05)$, showing $-35.14 \mathrm{mV}$ for caprine $\alpha_{\mathrm{S} 1} \mathrm{I}-\mathrm{CN}$ and $-34.80 \mathrm{mV}$ for caprine $\alpha_{\mathrm{S}_{1}} \mathrm{II}-\mathrm{CN}$, respectively. The lower zeta potentials of the oil droplets in the lutein-enriched emulsions stabilized by the caprine caseins compared with the lutein-enriched emulsions stabilized by bovine casein can imply a decreased net negative charge (Mora-Gutierrez et al., 1993). Differences in the AA side chains of $\kappa-\mathrm{CN}$, $\alpha_{S^{-}} \mathrm{CN}$, and $\beta-\mathrm{CN}$ fractions in caprine whole caseins, where the less charged $\beta$ quantitatively dominates,

Table 3. Particle size and zeta potential of oil droplets in luteinenriched emulsions stabilized by bovine and caprine caseins with and without added arabinogalactan in phosphate buffer at $\mathrm{pH} 7.0$ during storage for 1,48 , and $96 \mathrm{~h}$ at $25^{\circ} \mathrm{C}$

\begin{tabular}{lcc}
\hline Treatment & $\begin{array}{c}\text { Particle size } \\
(\mathrm{nm})^{1}\end{array}$ & $\begin{array}{c}\text { Zeta potential } \\
(\mathrm{mV})^{1}\end{array}$ \\
\hline Casein type & & \\
$\quad$ Bovine & $205.94 \pm 2.90$ & $-37.50 \pm 1.86^{\mathrm{a}}$ \\
$\quad$ Caprine $\alpha_{\mathrm{S} 1}-\mathrm{I}$ & $206.44 \pm 2.66$ & $-35.14 \pm 1.77^{\mathrm{b}}$ \\
$\quad$ Caprine $\alpha_{\mathrm{S} 1} \mathrm{II}$ & $206.56 \pm 2.66$ & $-34.80 \pm 2.46^{\mathrm{b}}$ \\
$\quad$ Additive & & \\
$\quad$ With arabinogalactan & $205.19 \pm 2.88^{\mathrm{b}}$ & $-35.41 \pm 2.10$ \\
$\quad$ Without arabinogalactan & $207.44 \pm 2.04^{\mathrm{a}}$ & $-36.22 \pm 2.55$ \\
Storage $(\mathrm{h})$ & & \\
1 & $205.11 \pm 2.30$ & $-36.67 \pm 1.66$ \\
48 & $206.83 \pm 2.48$ & $-35.74 \pm 2.47$ \\
96 & $207.00 \pm 3.07$ & $-35.03 \pm 2.64$ \\
\hline
\end{tabular}

$\overline{\mathrm{a}, \mathrm{b}}$ Means in the same column within each treatment with a different superscript are significantly different $(P<0.05)$.

${ }^{1}$ Mean value $\pm \mathrm{SE}$. could lead to less repulsive charge-charge interaction and this phenomenon can possibly explain their lower zeta potentials (Table 3 ). The zeta potentials of the oil droplets in lutein-enriched emulsions prepared with bovine and caprine caseins were not statistically different with the addition of arabinogalactan but still high enough to confer electrostatic repulsive force between the oil droplets (Table 3). Likewise, the zeta potentials of the oil droplets in the lutein-enriched emulsions prepared with the 2 caprine caseins were not affected by the addition of arabinogalactan (Table 3). No significant difference $(P>0.05)$ was observed in the zeta potentials of the oil droplets in lutein-enriched emulsions prepared with bovine and caprine caseins when stored under accelerated photo-oxidation conditions for 1,48 , and $96 \mathrm{~h}$ at $25^{\circ} \mathrm{C}$. The 2 -way and 3 -way interactions were not significant $(P>0.05)$ for particle size diameter and zeta potential of the oil droplets in the lutein-enriched emulsion stabilized by the bovine and caprine caseins. On the basis of these findings, we can conclude that the lutein-enriched emulsions prepared with bovine and caprine caseins exhibited relatively good physical stability (McClements, 2005).

\section{Chemical Stability of Lutein Emulsions Prepared with Bovine and Caprine Caseins}

The degradation of lutein in lutein-enriched emulsions may be complex, but some possible major causes are related to the increased specific surface area in the emulsions and the possible formation of free radicals during high-pressure homogenization (Boon et al., 2010). In this study, all the main effects (Table 4), and casein type $\times$ storage time and additive $\times$ storage time interactions (Table 5$)$ were significantly different $(P$ $<0.05)$ in lutein concentration. The concentrations of lutein were higher $(P<0.05)$ in the lutein-enriched emulsions prepared with caprine caseins compared with the bovine casein (Table 4). Moreover, lutein-enriched emulsions exhibited higher chemical stability when arabinogalactan was added (Table 4). Overall, higher concentrations $(P<0.05)$ of lutein were observed in the lutein-enriched emulsions prepared with caprine caseins compared with bovine casein during storage under accelerated photo-oxidation conditions at $25^{\circ} \mathrm{C}$ (Table 5). The data indicated that the degradation of lutein entrapped in the lutein-enriched emulsions prepared with caprine caseins was slower than in those prepared with bovine casein. The concentrations of lutein were higher $(P<0.05)$ with the addition of arabinogalactan in the lutein-enriched emulsions at 72 and $96 \mathrm{~h}$ of storage under accelerated photo-oxidation conditions at $25^{\circ} \mathrm{C}$ (Table 5). Bovine and caprine caseins have the ability to protect liposoluble bioactives 
Table 4. Concentration of lutein in lutein-enriched emulsions stabilized by bovine and caprine caseins with and without added arabinogalactan in phosphate buffer at $25^{\circ} \mathrm{C}$ and $\mathrm{pH} 7.0$ during storage time

\begin{tabular}{ll}
\hline Treatment & $\begin{array}{c}\text { Concentration } \\
\text { of lutein }(\mathrm{mg} / \mathrm{L})^{1}\end{array}$ \\
\hline Casein type & $230.97 \pm 10.09^{\mathrm{c}}$ \\
Bovine & $238.40 \pm 8.59^{\mathrm{b}}$ \\
Caprine $\alpha_{\mathrm{S} 1} \mathrm{I}$ & $241.73 \pm 7.16^{\mathrm{a}}$ \\
Caprine $\alpha_{\mathrm{S} 1} \mathrm{II}$ & \\
Additive & $239.58 \pm 8.18^{\mathrm{a}}$ \\
With arabinogalactan & $234.49 \pm 10.53^{\mathrm{b}}$ \\
$\quad$ Without arabinogalactan & \\
Storage (h) & $245.22 \pm 3.06^{\mathrm{a}}$ \\
1 & $242.61 \pm 5.16^{\mathrm{ab}}$ \\
24 & $239.33 \pm 6.64^{\mathrm{b}}$ \\
48 & $233.11 \pm 7.40^{\mathrm{c}}$ \\
72 & $224.89 \pm 8.80^{\mathrm{d}}$ \\
\hline 6
\end{tabular}

${ }^{\mathrm{a}-\mathrm{d}}$ Means in the same column within each treatment with a different superscript are significantly different $(P<0.05)$.

${ }^{1}$ Mean value $\pm \mathrm{SE}$.

including the carotenoids from oxidation effectively after binding with them (Mora-Gutierrez et al., 2010). The unadsorbed bovine and caprine caseins dissolved in the aqueous phase of the lutein-enriched emulsions may have formed complexes with metal ions $\left(\mathrm{Fe}^{3+}\right)$, thus preventing their contact with lutein. A reduced reactivity toward metal ions $\left(\mathrm{Fe}^{3+}\right)$, a lowered amount of reactive oxygen species generated during high-pressure homogenization, and enhanced photo-stability through the formation of lutein complexes with arabinogalactan in the lutein-enriched emulsions stabilized by bovine and caprine caseins may be responsible for enhanced chemical stability. The xanthophyll carotenoids lutein, astaxanthin, and zeaxanthin are sensitive to heat, light, and other oxidative stressors (Martínez-Delgado et al., 2017). Therefore, some loss of lutein in the luteinenriched emulsions stabilized by bovine and caprine caseins during storage under accelerated photo-oxidation conditions is to be expected (Table 5).
It is important that lutein does not degrade during storage, being available at the time of food consumption. The results of this study clearly indicated that the chemical stability of lutein in lutein-enriched emulsions was improved in the presence of caprine caseins after $48 \mathrm{~h}$ of storage under accelerated photo-oxidation conditions at $25^{\circ} \mathrm{C}$ (Table 5). Added arabinogalactan significantly $(P<0.05)$ enhanced the chemical stability of lutein-casein complexes in lutein-enriched emulsions during storage under accelerated photo-oxidation conditions for 72 and $96 \mathrm{~h}$ at $25^{\circ} \mathrm{C}$ (Table 5).

\section{CONCLUSIONS}

The results of this study show that the caseins isolated from caprine milks can contribute to the improvement of lutein's chemical stability in lutein-enriched emulsions from 48 to $96 \mathrm{~h}$ of storage under accelerated photo-oxidation conditions at $25^{\circ} \mathrm{C}$ compared with bovine casein. The improved chemical stability of lutein will be useful in the development of low-fat dairy-like beverages. It is believed that increased binding affinity of caprine caseins, in particular, caprine $\alpha_{\mathrm{S1}}$-II$\mathrm{CN}$, with lutein leads to improved chemical stability of lutein in lutein-enriched emulsions during storage. These findings stress the importance of choosing the appropriate type of casein for improving the chemical stability of lutein in low-fat dairy-like beverages. The combination of casein with arabinogalactan should also be considered based on the enhanced chemical stability exhibited by lutein in lutein-enriched emulsions during storage under accelerated photo-oxidation conditions at room temperature.

\section{ACKNOWLEDGMENTS}

This work was supported by Evans-Allen funding to the Cooperative Agricultural Research Center through

Table 5. Concentration of lutein as influenced by the interactions of casein type $\times$ storage time and additive $\times$ storage time

\begin{tabular}{|c|c|c|c|c|c|}
\hline \multirow[b]{2}{*}{ Treatment } & \multicolumn{5}{|c|}{ Hours $^{1}$} \\
\hline & 1 & 24 & 48 & 72 & 96 \\
\hline \multicolumn{6}{|l|}{ Casein type } \\
\hline Bovine & $242.50 \pm 2.88^{\mathrm{a}, \mathrm{A}}$ & $237.83 \pm 2.32^{\mathrm{ab}, \mathrm{B}}$ & $232.33 \pm 4.72^{\mathrm{bc}, \mathrm{B}}$ & $225.33 \pm 4.93^{\mathrm{c}, \mathrm{B}}$ & $216.83 \pm 5.85^{\mathrm{d}, \mathrm{B}}$ \\
\hline Caprine $\alpha_{\mathrm{S} 1}-\mathrm{I}$ & $245.67 \pm 2.66^{\mathrm{a}, \mathrm{A}}$ & $244.17 \pm 5.00^{\mathrm{a}, \mathrm{AB}}$ & $241.17 \pm 3.87^{\mathrm{ab}, \mathrm{A}}$ & $234.83 \pm 4.58^{\mathrm{b}, \mathrm{A}}$ & $226.17 \pm 7.25^{\mathrm{c}, \mathrm{A}}$ \\
\hline Caprine $\alpha_{\mathrm{S} 1}$-II & $247.50 \pm 1.05^{\mathrm{a}, \mathrm{A}}$ & $245.83 \pm 4.17^{\mathrm{a}, \mathrm{A}}$ & $244.50 \pm 4.23^{\mathrm{ab}, \mathrm{A}}$ & $239.17 \pm 4.54^{\mathrm{b}, \mathrm{A}}$ & $231.67 \pm 6.44^{\mathrm{c}, \mathrm{A}}$ \\
\hline \multicolumn{6}{|l|}{ Additive } \\
\hline With arabinogalactan & $246.22 \pm 2.49^{\mathrm{a}, \mathrm{A}}$ & $243.67 \pm 4.69^{\mathrm{a}, \mathrm{A}}$ & $241.33 \pm 6.67^{\mathrm{ab}, \mathrm{A}}$ & $236.67 \pm 6.54^{\mathrm{b}, \mathrm{A}}$ & $230.00 \pm 8.22^{\mathrm{c}, \mathrm{A}}$ \\
\hline Without arabinogalactan & $244.22 \pm 3.38^{\mathrm{a}, \mathrm{A}}$ & $241.56 \pm 5.66^{\mathrm{ab}, \mathrm{A}}$ & $237.33 \pm 6.34^{\mathrm{b}, \mathrm{A}}$ & $229.56 \pm 6.71^{\mathrm{c}, \mathrm{B}}$ & $219.78 \pm 6.18^{\mathrm{d}, \mathrm{B}}$ \\
\hline
\end{tabular}


USDA Cooperative State Research Service, Washington, DC.

\section{REFERENCES}

Acharya, D. P., L. Sanguansri, and M. A. Augustin. 2013. Binding of resveratrol with sodium caseinate in aqueous solutions. Food Chem. 141:1050-1054.

Ambrosoli, R., L. Di Stasio, and P. Mazzoco. 1988. Content of $\alpha_{\mathrm{S}_{1}-}$ casein and coagulation properties of goat milk. J. Dairy Sci. 71:2428.

Basch, J. J., H. M. Farrell Jr., R. A. Walsh, R. P. Konstance, and T. F. Kumosinski. 1989. Development of a quantitative model for enzyme-catalyzed time-dependent changes in protein composition of Cheddar cheese during storage. J. Dairy Sci. 72:591-603.

Boon, C. S., D. J. McClements, J. Weiss, and E. A. Decker. 2010. Factors influencing the chemical stability of carotenoids in foods. Crit. Rev. Food Sci. Nutr. 50:515-532.

Davidov-Pardo, G., C. E. Gumus, and D. J. McClements. 2016. Lutein-enriched emulsion-based delivery systems: Influence of $\mathrm{pH}$ and temperature on physical and chemical stability. Food Chem. 196:821-827.

Dickinson, E. 2010. Flocculation of protein-stabilized oil-in-water emulsions. Colloids Surf. B Biointerfaces 81:130-140.

Eisenhauer, B., S. Natoli, G. Liew, and V. M. Flood. 2017. Lutein and zeaxanthin-food sources, bioavailability and dietary variety in agerelated macular degeneration protection. Nutrients 9:1-14.

Faraji, H., and R. C. Lindsay. 2005. Antioxidant properties of bulk fish oils by dispersed sugars and polyhydric alcohols. J. Agric. Food Chem. 53:736-744.

Fiedorowicz, E., L. H. Markiewicz, K. Sidor, D. Światecka, A. Cieślińska, M. Matysiewicz, K. Piskorz-Ogórek, E. SienkiewiczSzłapka, M. Teodorowicz, A. Światecki, and E. Kostyra. 2016. The influence of breast milk and infant formulae hydrolysates on bacterial adhesion and Caco-2 cells functioning. Food Res. Int. 89:679-688.

Frede, K., A. Henze, M. Khalil, S. Baldermann, F. J. Schweigert, and H. Rawel. 2014. Stability and cellular uptake of lutein-loaded emulsions. J. Funct. Foods 8:118-127.

Galliano, F., R. Saletti, V. Cunsolo, S. Foti, D. Marletta, S. Bordonaro, and G. D'Urso. 2004. Identification and characterization of a new $\beta$-casein variant in goat milk by high-performance liquid chromatography with electrospray ionization mass spectrometry and matrix-assisted laser desorption/ionization mass spectrometry. Rapid Commun. Mass Spectrom. 18:1972-1982.

Jaubert, A., and P. Martin. 1992. Reverse-phase HPLC analysis of goat caseins. Identification of $\alpha_{\mathrm{S} 1}$ and $\alpha_{\mathrm{S} 2}$ genetic variants. Lait 72:235-247.

Kelkar, D., A. Chaudhuri, S. Haidar, and A. Chattopadhyay. 2010. Exploring tryptophan dynamics in acid-induced molten globule state of bovine $\alpha$-lactalbumin: A wavelength-selective fluorescence approach. Eur. Biophys. J. 39:1453-1463.

Krinsky, N. I., J. T. Landrum, and R. A. Bone. 2003. Biologic mechanisms of the protective role of lutein and zeaxanthin in the eye. Annu. Rev. Nutr. 23:171-201.

Kumosinski, T. F., E. M. Brown, and H. M. Farrell Jr.. 1993. Threedimensional molecular modeling of bovine caseins: An energy minimized beta-casein structure. J. Dairy Sci. 76:931-945.

Lakowicz, J. R. 2000. On spectral relaxation in proteins. Photochem. Photobiol. 72:421-437.

Lakowicz, J. R., and G. Weber. 1973. Quenching of protein fluorescence by oxygen. Detection of structural fluctuations in proteins on nanosecond time scale. Biochemistry 12:4171-4179.

Levine, R. L. 1977. Fluorescence quenching studies of the binding of bilirubin to albumin. Clin. Chem. 23:2292-2301.
Liang, L., and M. Subirade. 2010. $\beta$-lactoglobulin/folic acid complexes: Formation, characterization, and biological implication. J. Phys. Chem. B 114:6707-6712.

Liang, L., H. A. Tajmir-Riahi, and M. Subirade. 2008. Interaction of $\beta$-lactoglobulin with resveratrol and its biological implications. Biomacromolecules 9:50-56.

Liang, L., V. Tremblay-Hebert, and M. Subirade. 2011. Characterization of the $\beta$-lactoglobulin/ $\alpha$-tocopherol complex and its impact on $\alpha$-tocopherol stability. Food Chem. 126:821-826.

Martínez-Delgado, A. A., S. Khandual, and S. J. Villanueva-Rodríguez. 2017. Chemical stability of astaxanthin integrated into a food matrix: Effects of food processing and methods for preservation. Food Chem. 225:23-30.

McClements, D. J. 2005. Emulsion stability. Pages 269-339 in Food Emulsions: Principles, Practice, and Techniques. 2nd ed. CRC Press, Boca Raton, FL.

Meyer, M. C., and D. E. Guttman. 1968. The binding of drugs by plasma proteins. J. Pharm. Sci. 57:895-918.

Mitri, K., R. Shegokar, S. Gohla, C. Anselmi, and R. H. Müller. 2011. Lutein nanocrystals as antioxidant formulation for oral and dermal delivery. Int. J. Pharm. 420:141-146.

Mora-Gutierrez, A. 2016. Physicochemical and functional properties of native and trypsin-treated caprine casein micelles. Pages 27-45 in Caseins-Properties, Functions and Health Implications. Vol. 1. L. Mendoza, ed. Nova Science Publishers Inc., New York, NY.

Mora-Gutierrez, A., R. Attaie, and H. M. Farrell Jr.. 2010. Lipid oxidation in algae oil-in-water emulsions stabilized by bovine and caprine caseins. J. Agric. Food Chem. 58:5131-5139.

Mora-Gutierrez, A., R. Attaie, J. M. Kirven, and H. M. Farrell Jr.. 2014. Cross-linking of bovine and caprine caseins by microbial transglutaminase and their use as microencapsulating agents for n-3 fatty acids. Int. J. Food Sci. Technol. 49:1530-1543.

Mora-Gutierrez, A., H. M. Farrell Jr., and T. F. Kumosinski. 1993. Comparative thermodynamic linkage study of the calcium-induced solubility of bovine and caprine caseins. J. Agric. Food Chem. 41:372-379.

Mora-Gutierrez, A., T. F. Kumosinski, and H. M. Farrell Jr.. 1991. Quantification of $\alpha_{\mathrm{S}_{1}}$-casein in goat milk from French-Alpine and Anglo-Nubian breeds using reversed-phase high performance liquid chromatography. J. Dairy Sci. 74:3303-3307.

Polyakov, N. E., and L. D. Kispert. 2015. Water soluble biocompatible vesicles based on polysaccharides and oligosaccharides inclusion complexes for carotenoid delivery. Carbohydr. Polym. 128:207-219.

Sajilata, M. C., R. S. Singhal, and M. Y. Kamat. 2008. The carotenoid pigment zeaxanthin - A review. Compr. Rev. Food Sci. Food Saf. 7:29-49.

Salazar, N., A. Prieto, J. A. Leal, B. Mayo, J. C. Bada-Gancedo, C. G. de los Reyes-Gavilán, and P. Ruas-Madiedo. 2009. Production of exopolysaccharides by Lactobacillus and Bifidobacterium strains of human origin, and metabolic activity of the producing bacteria in milk. J. Dairy Sci. 92:4158-4168.

Sasaki, M., K. Yuki, T. Kurihara, S. Miyake, K. Noda, S. Kobayashi, S. Ishida, K. Tsubota, and Y. Ozawa. 2012. Biological role of lutein in the light-induced retinal degeneration. J. Nutr. Biochem. $23: 423-429$.

Selvaggi, M., V. Laudadio, C. Dario, and V. Tufarelli. 2014. Major proteins in goat milk: An updated overview on genetic variability. Mol. Biol. Rep. 41:1035-1048.

Steiner, R. F., J. Roth, and J. Robbins. 1966. The binding of thyroxine by serum albumin as measured by fluorescence quenching. J. Biol. Chem. 241:560-567.

Yi, J., Y. Fan, W. Yokoyama, Y. Zhang, and L. Zhao. 2016. Characterization of milk proteins-lutein complexes and the impact on lutein chemical stability. Food Chem. 200:91-97.

Zhang, Y., and Q. Zhong. 2012. Binding between bixin and whey protein at $\mathrm{pH} 7.4$ studied by spectroscopy and isothermal titration calorimetry. J. Agric. Food Chem. 60:1880-1886. 